\title{
DIÁLOGOS SOBRE GÊNERO E SEXUALIDADE NO ESPAÇO ESCOLAR: CONTRIBUIÇÕES À FORMAÇÃO HUMANA
}

\author{
JoÃo FERNANDO de ARAúJO \\ AdRIANA REGINA DE JESUS SANTOS \\ ADRIELEN AMANCIO DA SILVA \\ Marta Silene Ferreira BarRos \\ Universidade Estadual de Londrina (UEL), Londrina, Paraná, Brasil
}

\begin{abstract}
Resumo: A educação é o processo de transmissão da cultura elaborada pela humanidade. Assim, a escola passa a ser um importante espaço para a formação humana dos sujeitos. Por isso, temos como objetivo compreender como a escola, ao discutir gênero e sexualidade, contribui para a formação humana dos educandos e educandas, pois o gênero e a sexualidade são construções históricas, sociais e culturais que constituem a identidade de cada sujeito. A metodologia segue a abordagem qualitativa, desenvolvida em um estudo bibliográfico. Os resultados indicam que ao promover diálogos sobre as temáticas, a escola cumpre seu papel social no combate às desigualdades, valorização das culturas e dos sujeitos.
\end{abstract}

Palavras- chave: Educação. Gênero. Sexualidade. Formação Humana.

\section{CONSIDERAÇÕES INICIAIS}

Refletir sobre a formação humana requer sempre que voltemos nossos olhos para a escola, pois é nesse espaço, por meio da educação que nela se promove, que o sujeito tem a possibilidade de entrar em contato com os conhecimentos e saberes historicamente elaborados pelos seres humanos. Isto é, a escola possibilita o contato com outras culturas, outras vivências e experiências que nos levam a ampliar as maneiras de perceber e significar o mundo. Assim, temos como objetivo nessa pesquisa compreender a constituição da formação humana no contexto escolar, tendo como parâmetro as questões relacionadas ao gênero e sexualidade e suas implicações na formação do sujeito.

Como nos alerta Bourdieu (1998), temos observado que a escola tem sido um reflexo de uma sociedade desigual, que em alguns momentos apenas reproduz processos geradores de desigualdades e injustiças. Entretanto, a escola pode e deve funcionar como um importante espaço na luta contra essas desigualdades. Essa possibilidade já foi apontada por Gramsci (1979) e posteriormente por Saviani (1991), quando ambos assinalavam em seus pressupostos que essa instituição é um importante palco para a luta contra a hegemonia' que tanto assola a sociedade. Para tal feito, o trabalho pedagógico desenvolvido precisa estar pautado em ideais revolucionários, que 
levem os sujeitos a pensarem e não apenas reproduzirem práticas e pensamentos que alimentam as desigualdades e injustiças.

Sabemos que as desigualdades podem ser evidenciadas por diferentes aspectos, como etnia, classe social, entre outros. Aqui, nos ateremos àquelas que advêm das questões de gênero e sexualidade. Dessa forma, a problemática que norteia essa produção nos interroga sobre como a escola enquanto espaço formativo, ao promover diálogos sobre as questões de gênero e sexualidade, pode contribuir para a formação humana dos e das educandos e educandas?

Para responder tal indagação, esta pesquisa está pautada numa abordagem qualitativa. Nesta abordagem, segundo Flick (2009), tenciona-se estudar, entender, descrever e explicar os fenômenos sociais de diferentes maneiras como, por exemplo, por meio da análise de experiências individuais e grupais, investigação de documentos (textos, imagens, filmes, vídeos, músicas, obras de arte), entre outros modos. Utilizamos como método a pesquisa bibliográfica que, segundo Gil (2002, p. 44), "é desenvolvida com base em material já elaborado, constituído principalmente de livros e artigos científicos". Assim, discutiremos a formação humana dos sujeitos ancorados nas contribuições de Duarte (2014), Martins (2014), Mello (2009), Saviani (2011), enquanto as discussões sobre gênero e sexualidade estão pautadas nos pressupostos de autores como Louro (1997, 2011), Scott (1995), Foucault (1987), Butler (2019), entre outros.

A organização deste trabalho inicia-se com a discussão acerca de alguns conceitos e conhecimentos sobre a formação humana. Posteriormente, traçamos considerações conceituais sobre os marcadores sociais "gênero e sexualidade". Na sequência, elaboramos as discussões sobre a importância e as contribuições dos diálogos de gênero e sexualidade promovidos na escola para a formação humana dos sujeitos. Encerramos apresentando algumas considerações finais.

\section{REVISITANDO QUESTÕES SOBRE FORMAÇÃO HUMANA: PONDERAÇÕES NECESSÁRIAS}

Desde os primórdios, o caminhar da humanidade vem se desvelando por meio de manifestações de poder, de lutas e principalmente por meio de barbáries, talvez justificadas em remotos tempos históricos pela ausência do domínio da consciência dos nossos ancestrais, mas não mais aceitas hoje (ao menos esperamos que não sejam). No século XXI, almejamos que nossas sociedades superem comportamentos e pensamentos engendrados em premissas escravocratas, sexistas, patriarcais, burguesas, entre outras que tanto assolaram/assolam os povos ao longo da história.

A noção de revisitar a questão da formação humana se dá justamente porque os casos brutais de racismo, de homofobia, de feminicídio, de corrupção, de violências diversas, da cultura do ódio, entre tantos outros problemas, têm nos levado a questionar: somos mesmo humanamente desenvolvidos? Temos de fato uma formação que nos qualifique como seres, homens e mulheres, sociais e culturais? Se essas duas questões forem afirmativas, porque ainda excluímos, matamos, discriminamos as pessoas? Por mais desconfortável que seja, colocar em xeque a questão da formação humana nos parece ser o único meio para que possamos entender os problemas acima elencados e o meio pelo qual consigamos superá-los. 
Para que compreendamos essa formação dos sujeitos, é necessário deixar claro que ela é histórica, social e cultural, como bem apontam os estudos de Duarte (2014), Leontiev (1978), Malanchen (2019) e Bernardes (2012). Nascemos humanos, mas não somos plenamente humanos. Sobre isso, de modo excepcional, Duarte (2014, p. 38) assevera que

\begin{abstract}
Toda pessoa possui, ao nascer, a condição de um ser humano no sentido de que nasce pertencendo à espécie humana. Igualmente, ela é um ser humano singular no sentido de que se trata de um ser humano individualizado por características biológicas que herda geneticamente e que a singularizam como organismo. Aquele organismo ao nascer não é inteiramente igual a outros organismos humanos. Ele tem suas singularidades. Nesse sentido, bastante restrito, eu afirmaria: sim, toda pessoa nasce como um indivíduo humano. Por outro lado, eu afirmaria: ele nem é, ainda, plenamente um ser humano, nem é ainda plenamente um indivíduo.
\end{abstract}

Assim, temos a concepção de que embora pertencente ao gênero humano, ainda falta à pessoa em seus primeiros momentos de vida a apropriação de elementos que lhe tornem plenamente humana. Esses elementos nada mais são do que os instrumentos materiais e imateriais elaborados pelo conjunto dos homens e mulheres ao longo da história. Para esclarecer essas ideias, Duarte (2014, p. 39) afirma que "não nascemos com o essencial de nossa individualidade e de nossa humanidade. Mas aquilo de que precisamos para desenvolver essa individualidade e essa humanidade já existe na sociedade, ou seja, na cultura".

A partir dessas primeiras considerações, podemos perceber que a formação humana depende imprescindivelmente da cultura (LEONTIEV, 1978; DUARTE, 2014; MALANCHEN, 2019). Mas que cultura é essa? De que se tratam os tais instrumentos materiais e imateriais elaborados ao longo dos tempos pelo conjunto de homens e mulheres que trazem ao sujeito o que lhe falta para se tornar plenamente humano?

Num sentido mais amplo, Malanchen $(2019$, p. 51) esclarece que a cultura é "constituída pelo resultado da relação produtiva do ser humano sobre a natureza, ou seja, tudo aquilo que não é natural e tem atividade humana condensada, é cultura." Avaliamos, assim, que a cultura nasce da ação consciente do homem sobre a natureza, transformando-a para que possa produzir sua existência. E aqui nos ancoramos em estudos marxistas para refletirmos que por meio da ação do homem e da mulher sobre a natureza (e essa ação é a atividade vital humana, a qual conhecemos como trabalho) a cultura vai sendo produzida e acumulada.

Reafirmando tais aspectos constitutivos da cultura, Mello (2009, p. 365) infere que

A cultura é vista como fonte das qualidades criadas e desenvolvidas ao longo da história pelos homens e mulheres que nos antecederam e guarda, em repouso, como dizia Marx (2004), a energia humana, o movimento, o trabalho utilizado em sua constituição - em outras palavras - as capacidades, as habilidades ou aptidões formadas e desenvolvidas no mesmo processo de criação dos objetos da cultura. 
Essa contribuição possibilita evidenciar que a formação humana se dá pela apropriação dos elementos culturais produzidos pela humanidade, mas percebemos também que a cultura depende do homem e da mulher para que possa ser produzida e transmitida. Essa apropriação e transmissão ocorrem a partir da interação do homem e da mulher com outros homens, outras mulheres e ainda com o meio. As considerações de Malanchen (2019, p. 51) legitimam tais afirmações, pois segundo a referida autora "a cultura é um produto da existência do ser humano, resultado de sua vida concreta na sociedade em que vive e das condições principalmente sociais que o circunda".

Diante disso, podemos compreender a questão da cultura e de sua importância para a formação humana. Mas ainda é preciso esclarecer a questão da materialidade e imaterialidade dos elementos culturais. Para tanto, necessitamos entender que 0 homem e a mulher, ao agirem sobre a natureza por meio do trabalho, produzem os objetos, os instrumentos necessários à sua sobrevivência e existência. Esses objetos são os elementos materiais, físicos que são manuseáveis, palpáveis e que fornecem às pessoas condições de viver e fazer história. É dessa cultura material, como esclarece Malanchen (2019, p. 52), que "se desdobram os elementos que compõem a cultura não material ou simbólica, como: a linguagem, as ideias e o conhecimento".

Fica evidente que os elementos culturais imateriais correspondem aos processos metafísicos construídos no psiquismo do homem e da mulher para que eles se apropriem dos elementos materiais de forma que compreendam sua utilização e desenvolvam as habilidades necessárias para utilizá-lo em seu desenvolvimento e formação. Já os imateriais são produzidos e transmitidos pelo conjunto dos homens e mulheres de maneira a lhes possibilitar a compreensão do uso social daqueles materiais produzidos.

Diante disso, percebemos que a formação humana se dá pela apropriação da cultura historicamente elaborada pela humanidade, de forma que o sujeito entre em contato com o que de mais elaborado foi produzido, e passe a produzir sua própria existência a partir dessa apropriação. Todavia, Malanchen $(2019$, p. 52) ainda reitera que essa apropriação é "sempre um processo coletivo, ou seja, é necessária a existência de mediações para que a mesma seja transmitida e apropriada no processo de humanização". Assim, percebemos a necessidade da interação com outros sujeitos para nos apropriarmos da cultura. E nesse sentido destacamos a importância da escola como espaço fundamental para mediação. Trataremos mais sobre a escola no último tópico deste trabalho.

Em suma, reiteramos a afirmativa inicial da formação humana como um processo histórico, social e cultural. É histórico, pois depende de uma bagagem previamente elaborada ao longo do tempo e ainda porque essa formação não está pronta e nem acabada. Enquanto o homem e a mulher viverem, estarão em processo de formação. É social, porque depende da interação entre os sujeitos e a sociedade para que recebam a cultura que é produzida pelas gerações precedentes. Por último, é cultural, porque ela é a matéria prima da formação humana e é por meio da aquisição dos elementos culturais que podemos vislumbrar a humanização, processo este que se dá por meio das relações sociais estabelecidas entre os sujeitos. E, neste texto, teremos 
como recorte o espaço escolar, haja vista que é um território constituído de diversidades de gênero e sexualidade.

\section{GÊNERO E SEXUALIDADE: INFERÊNCIAS CONCEITUAIS}

A necessidade de ter o direito de viver a sexualidade e as identidades de gênero, a necessidade de uma vida digna, de ter igualdade de oportunidades na vida pública e privada surgem como uma premissa nas lutas de diversos movimentos sociais. Esses movimentos, enquanto politicamente organizados, tiveram visibilidade ao redor do mundo e, aqui no Brasil, mais especificamente, ganharam maior força a partir dos anos de 1970. Como destaque desses movimentos, que colocam em pauta discussões nunca antes pensadas, temos os movimentos feministas, que não apenas abalaram as estruturas da sociedade, mas também colocaram em xeque a própria maneira de fazer ciência, pois agora as mulheres, as crianças e os marginalizados deveriam estar no centro dessas discussões (SCOTT, 1995, LOURO, 1997; BUTLER, 2019). O direito de uma formação humana, sistematizada e elaborada, o direito de fazer parte da sociedade, não poderia continuar apropriado apenas por uma minoria branca, heterossexual e religiosa.

Mediante as contradições da sociedade, entretanto, ao passo que temos grandes avanços, também sofremos grandes retrocessos, principalmente quando tocamos em assuntos que buscam uma mudança estrutural, como é o caso do gênero e da sexualidade. Falar desses temas em meio aos estigmas carregados pelas heranças da sociedade patriarcal e machista nos mostra o quanto ainda temos que aprender sobre essas temáticas. Elas foram sendo designadas à condição de tabus, deturpadas de tal forma que passaram a ser consideradas uma ameaça à sociedade, uma ameaça à tradição e à moral familiar. A legitimação desse pensamento, como apontam os estudos de Paraíso (2016), foi sendo disseminada por grupos religiosos e conservadores que buscaram e buscam impedir que o gênero e a sexualidade sejam entendidos como particularidades dos sujeitos, como parte na nossa existência ${ }^{2}$. Os resultados das ações movidas por tais grupos conduziram as discussões acerca das temáticas ao silêncio e à proibição, principalmente no espaço escolar. Pensando nisso, nosso intuito é contribuir com reflexões e conhecimentos sobre o tema. Para tanto, a seguir teceremos elaborações conceituais sobre gênero e sexualidade.

Para que possamos entender tais conceitos, faz-se necessário repensarmos a questão do "sexo", pois ele abre o leque para entendermos a sexualidade e o gênero. $O$ sexo, para Scott (1995), assim como para Louro (1997), Pacheco e Filipak (2017), Abramovay, Castro e Silva (2004) e Bortolini (2011), se refere às questões e às condições biológicas de macho e fêmea. As pessoas nascem com órgãos genitais, porém a questão que nos cabe problematizar é que essa condição biológica não é um fator determinante daquilo que as pessoas são ou se tornarão, pois, como vimos nos tópicos anteriores, somos seres sociais, que se constituem a partir da cultura.

Entretanto, a relação de poder criada para silenciar esses corpos utiliza justamente o discurso do sexo como biologicamente definidor daquilo que somos e seremos até o fim da vida. E essa lógica de ser e estar não "regula" apenas a sexualidade, mas o lugar que se deve ocupar dentro dela, assim como a maneira pela qual devemos nos comportar. Ao passo que se desloca dessa lógica, esse corpo é tido como anormal, como abjeto, que precisa ser eliminado. 
À luz dos postulados de Foucault (1988, p. 82), entendemos que "a lógica do poder sobre o sexo seria a lógica paradoxal de uma lei que poderia ser enunciada como injunção de inexistência, de não-manifestação e de mutismo". Essa assertiva que enfatiza as relações entre poder e sexo, nos ajuda também a perceber parâmetros entre o poder, o gênero e a sexualidade. Embora já alertado de antemão por Foucault, a tentativa de silenciar os debates sobre os referidos marcadores sociais perdura fortemente ainda hoje, e é nesses contextos que precisamos trabalhar, esclarecendo, problematizando e desconstruindo essas relações de poder que excluem o outro.

Engajados em cessar com esses cenários, os movimentos feministas contribuíram e continuam a contribuir com o fortalecimento de pesquisas e debates que ajudam a romper com a ideia sobre os fatores biológicos como os únicos definidores da sexualidade e gênero dos sujeitos. Louro $(1997$, p. 22) esclarece que "não é negada a biologia, mas enfatizada, deliberadamente, a construção social e histórica produzida sobre as características biológicas". O que pretendemos é ir além dos limites impostos ao sexo pela biologia. Quando superamos esses limites, nos deparamos com a sexualidade.

Esta, para Ribeiro (2007, p. 08), trata-se de uma "construção histórica, cultural e social, que articula saberes e poderes para o governo do sexo por meio dos corpos e das maneiras das pessoas viverem seus prazeres". Assim, a sexualidade se refere às maneiras de viver e experienciar o sexo. A sexualidade permite ao sujeito descobrir o sexo, o corpo e seus prazeres. Permite que existam outras relações, o que dá condições para que haja interações (entendam essas interações como relações de prazer, atrações, vínculos afetivos conjugais, atração sexual etc.). Enfim, a sexualidade rompe com a ideia do binarismo, possibilitando aos sujeitos relações heterossexuais ao mesmo passo que possibilita relações homossexuais, bissexuais, pansexuais, assexuais, dentre tantas outras formas de vivê-la.

O gênero por sua vez, num sentido mais amplo, nas considerações de Scott $(1995$, p. 75$)$, "trata-se de uma forma de se referir às origens exclusivamente sociais das identidades subjetivas de homens e de mulheres. Gênero é, segundo esta definição, uma categoria social imposta sobre um corpo sexuado". Temos assim, a ideia de gênero como um elemento constitutivo da subjetividade humana, revelando-se como um aspecto da identidade de homens e mulheres a partir de sua sexualidade. Cabe esclarecer, porém, como afirma Scott $(1995$, p. 76), que "o uso de 'gênero' enfatiza todo um sistema de relações que pode incluir o sexo, mas não é diretamente determinado pelo sexo, nem determina diretamente a sexualidade".

Nessa perspectiva, percebemos o gênero para além do sexo e destacamos então o caráter social, histórico e cultural que formam o gênero em suas mais diversas identidades. Butler (2019, p. 56) nos revela que "[...] o gênero é sempre um feito, [...] não há identidade de gênero por trás das expressões de gênero; essa identidade é performativamente constituída pelas próprias 'expressões' de gênero". O gênero está relacionado com a maneira de ser do sujeito, está imbricado em sua personalidade, em suas ações, regula suas práticas corporais e sexuais de forma que o permita se sentir e se perceber. Como nossas práticas não são lineares, há uma quebra de algo prédeterminado tanto biológico como culturalmente, em um sentido fixo. Por isso, quando 
os corpos não são coerentes com a lógica heterossexual, ele ataca o sistema de podersaber, pois ele não serve mais para explicar o gênero, o sexo e a sexualidade.

Em meio a todas essas questões temos a identidade. Quando tratamos dela, estamos nos referindo "aquilo que se é" (SILVA, 2000, p. 74), ao modo como os sujeitos são, se percebem e se apresentam no mundo. A identidade corresponde ao que o sujeito é. Há de se atentar, no entanto, para o movimento contínuo da formação identitária, pois longe de ser consolidada, acabada e fixada, ela consiste numa "celebração móvel: formada e transformada continuamente em relação às formas pelas quais somos representados ou interpelados nos sistemas culturais que nos rodeiam." (HALL, 2006, p. 12). Assim, identidade corresponde a aquilo que o sujeito é, seus pensamentos, comportamentos, crenças e maneiras de ser e estar no mundo. Em contínuo processo de formação e transformação, por conta das influências históricas, sociais e culturais que circundam e constituem a vida dos sujeitos, a identidade será desenvolvida por toda a existência desses sujeitos.

Dessa maneira, evidenciamos o gênero e a sexualidade como construções históricas, primeiramente porque acompanham o sujeito ao longo de sua existência e porque também são aspectos que vão sendo ressignificados ao longo dos tempos pelos mais variados grupos sociais. Assim, são também construções sociais porque estão diretamente ligadas a um conjunto de práticas que são legitimadas ou negadas pela sociedade, o que influencia diretamente em suas atuações particulares e sociais. São culturais porque é por meio da cultura que o gênero e a sexualidade são significados e ressignificados, e coexistem nesse movimento de luta, poder e resistência.

A partir dessas premissas conceituais, e tendo também o gênero como uma ferramenta política e teórica, utilizamos das contribuições de Meyer (2013) para contextualizar o nosso ponto de partida. Pensar a formação humana, nas escolas, a partir de um estudo para a igualdade de gênero, nos leva também a compreender que: 1- "[...] ao longo da vida, através das mais diversas instituições e práticas sociais, nos constituímos como homens e mulheres, num processo que não é linear [...]" (MEYER, 2013, p. 18); 2- "[...] como nascemos e vivemos em tempos, lugares e circunstâncias específicos, existem muitas e conflitantes formas de viver a feminilidade e a masculinidade" (MEYER, 2013, p. 19); 3- "[...] as análises e as intervenções empreendidas devem considerar, ou tomar como referências, as relações - de poder - entre homens e mulheres e as muitas formas sociais e culturais que constituem como 'sujeitos de gênero'" (MEYER, 2013, p. 20); 4- A aproximação de abordagens mais amplas que considerem que as instituições sociais, os símbolos, as normas, os conhecimentos, as leis, as doutrinas e as políticas são constituídas e atravessadas por representações e pressupostos de masculinidades e feminilidades, ao mesmo tempo em que podem contribuir para a sua produção, manutenção ou ressignificação (MEYER, 2013).

Desse modo, no próximo tópico aproximamos melhor das nossas análises e reflexões, uma vez que nossa maior intenção é pensar a formação humana no contexto escolar, tendo como parâmetro as relações de gênero e sexualidade, pois estas, como vimos, estão intimamente ligadas à formação dos sujeitos.

DISCUSSÃO DE GÊNERO E SEXUALIDADE NA ESCOLA: REFLEXÕES SOBRE FORMAÇÃO HUMANA 
Ante as considerações acima apresentadas, há um ponto na questão da formação humana que nos direciona a olhar para a escola. Trata-se da questão da diversidade cultural, de gênero e sexualidade. Isto é, a escola funciona, segundo Bortolini (2011, p. 28), como "uma arena cultural" pelo fato de que nela entram em confronto diferentes sujeitos, com variadas culturas e distintas maneiras de enxergar e significar o mundo. Nesse sentido, o trabalho educativo desenvolvido no seio das escolas precisa ser bem planejado de forma a privilegiar e valorizar todas as formas culturais para que os sujeitos recebam o que de mais elaborado foi produzido. Isso culminará numa humanização mais rica e significativa para os sujeitos.

É evidente que a escola não é o único espaço onde o sujeito entra em contato com a cultura, mas ela é locus privilegiado onde deverá, de forma planejada e sistematizada, organizar o saber. Conforme afirma Saviani (2011, p. 14), "a escola é uma instituição cujo papel consiste na socialização do saber sistematizado". Em outras palavras, à escola cabe socializar a cultura erudita.

Por meio dessas condições, revela-se a importância da educação no processo de formação humana que aqui tratamos, pois é necessário entendermos que "o trabalho educativo é o ato de produzir, direta e intencionalmente, em cada indivíduo singular, a humanidade que é produzida histórica e coletivamente pelo conjunto dos homens [e mulheres]" (SAVIANI, 2011, p. 13, acréscimo nosso). Evidenciamos, assim, que é por meio da educação que transmitimos (sabendo que o sentido dessa transmissão não é o mesmo daquela apresentada pelas práticas tradicionais) o "patrimônio material e intelectual produzido historicamente, não se instituindo de modo natural ou espontâneo" (MARTINS, 2014, p. 107).

Para tanto, Saviani $(2011$, p. 13) explica:

[...] o objeto da educação diz respeito, de um lado, à identificação dos elementos culturais que precisam ser assimilados pelos indivíduos da espécie humana para que eles se tornem humanos e, de outro lado e concomitantemente, à descoberta das formas mais adequadas para atingir esse objetivo.

Dessa maneira, à escola cabe selecionar, sistematizar e organizar os conteúdos de forma que esses possam contemplar o que de mais desenvolvido há em termos de elementos culturais materiais e imateriais. Mello $(2009$, p. 369) afirma que "essa relação com a cultura não acontece só na escola, mas a escola tem como função essencial proporcionar uma linguagem de mediação intencionalmente voltada para o ensino, para aprendizagem e para o desenvolvimento humano".

E aqui destacamos o papel da escola como ambiente de interação, socialização e mediação entre os sujeitos. Para Bernardes (2012), "no processo de apropriação da cultura, decorrente das atividades humanas em geral, a mediação é identificada como categoria fundamental para a compreensão do desenvolvimento humano". É por meio da mediação que as experiências e os conhecimentos são trocados entre um sujeito e outro. Para sintetizar tais questões, Mello (2009, p. 366), de forma muito esclarecedora, infere que 
[...] apropriar-se da cultura significa apropriar-se do uso social para qual os elementos da cultura foram criados [...]. Para aprender o uso social dos objetos, as novas gerações não podem simplesmente inventar, mas precisam aprender com quem conhece. Esses parceiros mais experientes medeiam para as novas gerações 0 acesso à cultura.

Contribuindo com essa reflexão, Mello (2009, p. 367) ainda assevera que é "sob a forma de experiências, vivências e situações, que o professor intencionalmente produz o processo de humanização, ou seja, o processo de constituição do humano nas novas gerações". Sendo assim, podemos entender que a escola se constitui como um espaço de socialização e interação. Isso possibilita que o/a professor/professora possa mediar, por meio da linguagem direcionada às novas gerações, o arsenal cultural produzido pela humanidade, pois é por meio da apropriação dos elementos culturais que o ser humano desenvolve suas capacidades cognitivas. À medida que essas qualidades psíquicas são desenvolvidas, a consciência do sujeito vai sendo produzida. Essa consciência permite ao sujeito perceber a realidade de forma objetiva, tal qual ela é.

É um importante fator quando pensamos na questão da formação desse sujeito por meio de suas ações no mundo. Essa mudança ocorre, porque, ao nascer, o ser é regido pelas leis da natureza e por isso tende a agir com espontaneidade, instintivamente. Somente por meio do contato com a cultura é que ele passará a ter consciência de seus atos e não mais será guiado pelos impulsos naturais. Passará, então, a atender às demandas sócio-históricas.

Ressaltamos, dessa maneira, que a escola é um campo de diversidades, onde se encontram diversas culturas e distintos sujeitos sócio-históricos. Evidenciamos essa instituição como lócus de socialização, interação e mediação por meio do qual há trocas de conhecimentos educacionais entre os que ocupam esses espaços. Esse processo pode implicar na formação do sujeito novas maneiras de enxergar e significar o mundo e a sociedade, tendo como parâmetro um olhar pautado na alteridade e não na homogeneidade dos indivíduos.

A sociedade tem se desenvolvido de forma segregacionista, excludente e violenta; muitos grupos sociais seguem sendo marginalizados (a conotação à qual nos referimos é aquela relacionada a estar à margem), silenciados, violentados e brutalmente assassinados. Por isso, discussões sobre gênero e sexualidade no espaço escolar vem como uma maneira fundamental de contribuir para a formação humana dos sujeitos.

Retomamos, dessa forma, os questionamentos que deram início a essa reflexão: Somos mesmos humanamente desenvolvidos? Temos de fato uma formação que nos qualifique como seres, homens e mulheres, sociais e culturais? Se essas duas questões forem afirmativas, porque ainda excluímos, matamos, discriminamos as pessoas? Assim, reafirmamos a essencialidade da educação escolar para conseguirmos não apenas responder esses questionamentos, mas refletir sobre porque ainda precisamos trazê-los para o centro da discussão.

Os estudos de Louro (2011, p. 65) nos esclarecem que

No contexto da sociedade brasileira, ao longo de sua história, foi sendo produzida uma norma a partir do homem branco, 
heterossexual, de classe média urbana e cristão. Essa é nossa identidade referência, a identidade que não precisa ser mencionada porque é suposta, está subentendida. Por isso os "outros", os sujeitos "diferentes", os "alternativos" ou os "problemáticos" serão, em princípio, as mulheres, as pessoas não brancas, as não heterossexuais ou não-cristãs.

Essa assertiva nos chama atenção para o processo de construção de uma norma que coloca como referência um suposto padrão ideal. A imposição dessa regra é o que tem ocasionado a marginalização dos sujeitos que fogem desse padrão. Ao retomarmos o conceito de cultura como tudo aquilo que foi elaborado materialmente e imaterialmente pelo conjunto dos homens e mulheres, podemos avaliar que a nossa cultura tem produzido exclusão, tem silenciado vozes e principalmente desvalorizado as diferenças que, na verdade, têm sido vistas como algo negativo, como algo que incomoda e ameaça.

Precisamos urgentemente repensar o papel da escola na formação dos sujeitos. Mello (2009, p. 66) aponta que "o ser humano se constitui como ser humano nos processos de vida e educação que experimenta, ou seja, aprende a ser humano nas relações sociais de que participa como sujeito ativo". Tal premissa nos traz reflexões preocupantes, pois se a formação e o desenvolvimento da pessoa se dão ao passo que ela participa das relações sociais como sujeito ativo, como aqueles e aquelas marginalizados/as e excluídos/as têm se desenvolvido? Que tipo de cultura vem sendo transmitida pela escola que estabelece superioridade a um grupo em detrimento de outro? Qual fundamento concreto tem sido utilizado para justificar essa construção? Se a cultura é elaborada por nós e para nós, seres humanos, por que não é conferido o mesmo valor a todos para recebê-la ou produzi-la?

São questões que necessitam de atenção, reflexões e práticas que rompam com esse modelo excludente. Num país em que mulheres, homossexuais e negros são assassinados com violência bárbara todos os dias, a escola não pode se calar e ser conivente com essa condição. Rodrigues (1991 apud GATTI, 2013, p. 54), ponderando sobre o papel da educação básica,

[...] a coloca como respondendo ao processo mínimo indispensável para que todos os indivíduos de uma determinada sociedade histórica completem a sua adequada formação humana, de modo a que se tornem um ente cultural, defendendo que todos têm o direito de posse dos instrumentos necessários à vida moderna. Trata-se aqui de qualidade educativa.

Nesse sentido, evidenciamos a importância da escola assumir o papel na luta pela valorização da diversidade e do respeito. A escola necessita adotar uma postura de transformação da realidade social e promover diálogos sobre gênero e sexualidade é um passo importante para isso. Não podemos mais segregar essas temáticas na esfera do privado, pois elas estão relacionadas com a nossa construção social, histórica e cultural. A partir do momento que gênero e sexualidade são colocados como um dos muitos saberes elaborados pela sociedade, iniciamos uma importante curva para a 
desconstrução de preconceitos, problematização de únicas formas de ser, estar, sentir e viver a sexualidade, a identidade, o gênero, e desnaturalizamos a violência.

É necessário que a escola rompa com paradigmas homogêneos e se posicione a favor da diversidade, entendendo-a como uma importante fonte de cultura. Ao debater as temáticas, a escola dará voz aos grupos antes silenciados, Ihes dando a possibilidade de participar ativamente da sociedade a qual compõem, bem como a escola estará, por meio dessas discussões, fazendo valer os direitos humanos garantidos na Constituição Federal, fortalecendo o sentido da formação humana.

\section{APONTAMENTOS FINAIS}

Repensar a formação humana dos sujeitos é papel primordial da escola, uma vez que é nela que acontece a sistematização do saber e a transmissão do arcabouço cultural historicamente elaborado pelo conjunto de homens e mulheres. Desse modo, a escola, enquanto espaço formativo, ao promover diálogos sobre as questões de gênero e sexualidade, contribui para a formação humana dos educandos e educandas, pois concede vez e voz aos inúmeros sujeitos que historicamente foram/são silenciados por conta das desigualdades.

Pensando nesse aspecto da formação humana, significa que a escola oferta, por meio da educação, a possibilidade de todos os sujeitos terem suas existências respeitadas e seus direitos garantidos. Significa reconhecer que todos esses sujeitos são diferentes e essas diferenças compõem identidades, que são todas legítimas e importantes. Claro que esse processo não é algo espontâneo, ou que apenas trazer essas temáticas de forma aleatória e pontual nas aulas iria desenvolver essa formação ou uma transformação social instantaneamente. É um processo contínuo que precisa ser reafirmado, repensado, trabalhado, discutido, pois como vimos sempre há embates dos que tentam silenciar essas vozes. É um constante caminhar.

Discutir esses marcadores sociais contribui para que as desigualdades sejam percebidas e questionadas. Contribui não apenas para os profissionais da educação reavaliarem sua própria atuação, enquanto profissionais que medeiam essa formação, como também ajuda os educandos e educandas a se perceberem dentro da história, da cultura, como parte desse processo. Assim, a escola está consolidando seu papel na luta e resistência contra essas desigualdades e ainda corroborando para a formação de uma sociedade mais humana, justa e igualitária.

Artigo recebido em: 19/08/2020 Aprovado para publicação em: 30/12/2020

\section{DIALOGUES ON GENDER AND SEXUALITY IN SCHOOL SPACE: CONTRIBUTIONS TO HUMAN FORMATION}

ABSTRACT: Education is the process of transmitting the culture elaborated by humanity. So, the school becomes an important space for the human formation of the subjects. Therefore, we aim to 
understand how the school, when discussing gender and sexuality, contributes to the human formation of students and students, since gender and sexuality are historical, social and cultural constructions that constitute the identity of each subject. The methodology follows the qualitative approach, developed in a bibliographic study. The results indicate that by promoting dialogues on the themes, the school fulfills its social role in combating inequality, valuing cultures and individuals.

KEYWORDS: Education. Gender. Sexuality. Human Formation.

\section{DIÁLOGOS SOBRE GÉNERO Y SEXUALIDAD EN EL ESPACIO ESCOLAR: CONTRIBUCIONES A LA FORMACIÓN HUMANA}

RESUMEN: La educación es un proceso de transmisión de cultura diseñado para la humanidad. Así, la escuela se convierte en un espacio importante para la formación humana de pequeños sujetos. Por tanto, nuestro objetivo es comprender cómo la escuela, al hablar de género y sexualidad, contribuyó a la formación humana de estudiantes, ya que el género y la sexualidad son construcciones históricas, sociales y culturales que constituyen la identidad de cada sujeto. La metodología sigue un enfoque cualitativo, desarrollado en un estudio bibliográfico. Los resultados indican que, al promover el diálogo sobre los temas, la escuela cumpliendo su rol social no combate las desigualdades, la valorización de las culturas y de ambos sujetos.

PALABRAS CLAVE: Educación. Género. Sexualidad. Formación Humana.

NOTAS

1 - Ancorados nos pensamentos de Gramsci (1979) e Gruppi (1978), entendemos a hegemonia como as relações entre estruturas e superestruturas, de forma que há um distanciamento de uma para a outra. Esse distanciamento condiciona centralidade às superestruturas e inferioriza as estruturas de tal forma que há dominação da primeira sobre a segunda. Nessas condições, nesse texto nos referimos às hegemonias heteronormativa, patriarcal e conservadora que predominam na nossa sociedade.

2 - A exemplo dessas ações temos os inúmeros Projetos de Leis como o "Escola sem Partido", que prega a ideia de uma "ideologia de gênero" inventada por esses próprios grupos. Frigotto (2019, p. 19) contribui nessa reflexão ao mostrar que o "Escola sem Partido" é uma "esfinge e o ovo da serpente que ameaça a educação e a sociedade brasileira".

\section{REFERÊNCIAS}

ABRAMOVAY, M.; CASTRO, M.; G. SILVA, L. B. da. Juventudes e sexualidade. Brasília: UNESCO Brasil, 2004. 
ARAúJO, J. F. de; SANTOS, A. R. de J.; SILVA, A. A. da; BARROS, M. S. F.

BERNARDES, M. E. M. O desenvolvimento humano e a apropriação da cultura. In. BERNARDES, M. E. M. Mediações simbólicas na atividade pedagógica: contribuições da Teoria Histórico-Cultural para o ensino e a aprendizagem. Curitiba- Paraná: Editora CRV. p. 29-77. 2012.

BORTOLINI, A. Diversidade sexual e de gênero na escola. Revista Espaço AcadêmicoDossiê: Homofobia, sexualidade e direito: Rio de Janeiro. n 123, p. 27-37. 2011.

BOURDIEU, P. Escritos de educação. Petrópolis: Vozes. 1998.

BUTLER, J. Problemas de gênero: feminismo e subversão da identidade. Tradução de Renato Aguiar. 18 ed. Rio de janeiro: Civilização Brasileira, 2019.

DUARTE, N. A Pedagogia Histórico Crítica e a formação da individualidade para si. In: ORSO, P. J. SILVA, J. C. da. et. al. (orgs.). Pedagogia Histórico Crítica, educação brasileira e os desafios de sua institucionalização. Curitiba- Paraná: Editora CRV. p. 3347. 2014.

FLICK, U. Desenho da pesquisa qualitativa. Porto Alegre: Artmed, 2009.

FOUCAULT, M. História da Sexualidade: A vontade de saber. Maria Thereza da Costa Albuquerque e J.A. Guilhon Albuquerque (Trad.). 13 ed. Rio de Janeiro: Edições Graal. 1988.

FRIGOTTO, G. A Gênero das teses do Escola sem Partido: esfinge e ovo da serpente que ameaçam a sociedade e a educação. In: FRIGOTTO, G. Escola Sem Partido: esfinge que ameaça a educação e a sociedade brasileira. 2 ed., Rio de Janeiro: UERJ, LPP, 2019.

GATTI, B. Educação, escola e formação de professores: políticas e impasses. Educar em Revista. Curitiba: Editora UFPR. n. 50, p. 51-67, out./dez. 2013.

GIL, A. C. Como elaborar projetos de pesquisa. 4. ed. São Paulo: Atlas, 2002.

GRAMSCl, A. Os intelectuais e a organização da cultura. Rio de Janeiro: Civilização brasileira. 1979.

GRUPPI, L. O conceito de hegemonia em Gramsci. Tradução de Carlos Nelson Coutinho. Rio de Janeiro: Graal, 1978.

HALL, S. A identidade cultural na pós-modernidade. Tradução de Tomaz Tadeu da Silva e Guaracira Lopes Louro. 11 ed. Rio de Janeiro: DP\&A. 2006.

LEONTIEV, A. N. O desenvolvimento do psiquismo. Lisboa: Livros Horizonte, 1978.

LOURO, G. L. Gênero, sexualidade e educação: Uma perspectiva pós-estruturalista. Petrópolis, RJ: Vozes, 1997. 
LOURO, G. L. Educação e docência: Diversidade, gênero e sexualidade. Formação Docente, Belo Horizonte, v.3, n.4, p.62-70, jan./jul. 2011.

MALANCHEN, J. Cultura, processo de humanização e emancipação humana definição e compreensão a partir da teoria marxista. In: BARROS, M. S. F., PASCHOAL, J. D.

PADILHA, A. (orgs.). Formação, ensino e emancipação humana: desafios da contemporaneidade para a educação escolar. Curitiba-Paraná: Editora CRV. p. 43- 53. 2019.

MARTINS, L. M. A constituição histórico-social da subjetividade humana: contribuições para a formação de professores. In: MILLER, S. BARBOSA, M. V. MENDONÇA, S. G. de L. Educação e Humanização: as perspectivas da teoria histórico cultural. Jundiaí-São Paulo: Paco Editorial. p. 97- 110. 2014.

MELLO, S. A. Cultura, mediação e atividade. In: MENDONÇA, S. G. de L. SILVA, V. P. MILLER, S. (orgs.). Marx, Gramsci e Vigotski: aproximações. Araraquara-São Paulo: Cultura Acadêmica. p. 365- 376. 2009.

MEYER, D. E.. Gênero e educação: teoria e política. In. LOURO, Guacira Lopes; FELIPE, Jane; GOELLNER, Silana Vilodre (orgs.). Corpo, Gênero e sexualidade: Um debate contemporâneo na educação. 9 ed. Petrópolis, RJ: Vozes, 2013.

PACHECO, E. F. H.; FILIPAK, S. T.. Relações de gênero e diversidade sexual na educação. Psicologia Argumento, v.35, n.88, p. 63-81, jan/abr., 2017.

PARAÍSO, M. A. A ciranda do currículo com gênero, poder e resistência. Revista Currículo sem Fronteiras. v. 16, n. 3, p. 388-415, set./dez. 2016.

RIBEIRO, P. R. C. Corpos, Gêneros e Sexualidades: questões possíveis para o currículo escolar. Caderno Pedagógico Anos Iniciais. Rio Grande: Editora da FURG, 2007.

SAVIANI, D. Escola e Democracia. São Paulo: Cortez. 1991.

SAVIANI, D. Pedagogia Histórico-crítica: primeiras aproximações. 11 ed. Campinas, SP: Autores Associados. 2011.

SCOTT, J. W. Gênero: uma categoria útil de análise histórica. Educação \& Realidade. Revisão de Tomaz Tadeu da Silva. Porto Alegre, v.20, n.2, jul./dez. p. 71-99. 1995.

SILVA, T. T. da. A produção social da identidade e da diferença. In: SILVA, Tomaz Tadeu da (Org). Identidade e diferença: a perspectiva dos estudos culturais. Petrópolis, RJ: Vozes, 2000. 
JoÃo Fernando de Araújo: Mestrando em Educação pela Universidade Estadual de Londrina- UEL.

Orcid: http://orcid.org/0000-0003-0262-1604

E-mail: joaofernandojbt@hotmail.com

Adriana Regina de Jesus SAntos: Possui graduação em Pedagogia e Especialização em Sociologia da Educação pela Universidade Estadual de Londrina (1998), Mestrado em Educação pela Universidade Estadual de Ponta Grossa (2003). Doutorado em Educação pela Pontifícia Universidade Católica de São Paulo. Pós Doutora em Educação pela Universidade Federal Fluminense (Bolsista PNPD/CAPES). É professora dos Cursos de Pedagogia, do Curso de Especialização em Docência na Educação Superior e do Programa de Pós- graduarão em educação da Universidade Estadual de Londrina.

Orcid: https://orcid.org/0000-0002-9346-5311

E-mail: adrianatecnologia@yahoo.com.br

Adrielen Amancio da Silva: Mestra em Educação pelo Programa de Pós-Graduação em Educação da Universidade Estadual de Londrina, com Bolsa da Capes. Formada em Pedagogia pela Fundação Universidade Federal de Rondônia - UNIR, Campus de JiParaná.

Orcid: https://orcid.org/0000-0003-1913-9646

E-mail: adrielen.amancio@gmail.com

Marta Silene Ferreira Barros: Possui graduação em Pedagogia pela Universidade Estadual da Paraíba - UEPB (1991); Bacharela em Psicologia pela Faculdade Ingá UNINGÁ (2008); Especialista pela Universidade Estadual de Maringá - UEM (1995). Mestrado em Educação (Filosofia da Educação) pela Universidade Metodista de Piracicaba - UNIMEP (1998). Doutorado em Educação pela Universidade de São Paulo - USP (2004). Doutorado Sanduíche em Sociologie de L'éducation pela Université Charles-de-Gaulle em Lille - França (2002-2003). Pós-Doutorado em Educação pela UNESP de Marília - SP (2016).

Orcid: https://orcid.org/0000-0002-1924-8490

E-mail:mbarros_22@hotmail.com

Este periódico utiliza a licença Creative Commons Attribution 3.0, para periódicos de acesso aberto (Open Archives Initiative - OAI). 